\title{
How can Europe tackle the three employment challenges: the digital, the climate and the pandemic transition?
}

\author{
Allan Larsson \\ Kenneth Abrahamsson
}

\section{Abstract}

Never before in modern times has Working Europe been faced with such a fundamental and far-reaching transition pressure. We are at the beginning of two powerful transition processes, the innovation-driven digital transformation, and the policy-driven climate transition. On the top of these processes, we are now facing a pandemic-driven restructuring of important sectors of our economies. Are our labour market regimes and policies fit for these challenges? Are we finally witnessing "the end of work" and an extended period of being "Left Behind"? Or can we build up capacities to deal with these three fundamental challenges? In this paper the authors discuss these issues based on the most recent labour market research and statistics, and present some preliminary conclusions on the new forms of transition mechanism, and the scaling-up of European and national labour market transition policies as part of the Next Generation EU recovery strategy. It is not easy to predict the content, quality and volume of skill development needs caused by the triple challenge of climate change, digitalisation, and Covid-19. We suggest, however, that the EU Commission should develop a transition capacity indicator corresponding to at least one fifth of the labour force and to recommend new springboards and bridges to work for the next years to come. We are convinced that this is the most productive and profitable investment Europe can make.

Keywords: Digitalisation, climate change, green deal, Covid-19, just transition, skill gap

\section{The twin challenges of digitalisation and climate transition}

The increasingly significant element in the 2020s is that the transformation of society, enterprises, and workplaces will be driven by two strong forces: the energy- and climate transition to low carbon-energy and renewable energy, and the ongoing digital transformation in its many new forms such as Al, IOT, 5G and Big Data. Electricity 4.0 is a 
necessary precondition for Industry 4.0, and illuminates the emerging symbioses between the challenges of digitalisation and climate transition. By using the concept of Electricity 4.0, we want to highlight the need and importance of new zero-carbon energy systems in a future perspective. It is a twin concept to Industry 4.0, which is more familiar and has been used for some years. Together, they are core actors in the transformation on European workplaces and societies. The Swedish Climate Policy Council underlines the need for new and heavy infrastructure investments. In conclusion, the obstacles to the industrial sector's transition involve the need for new technologies and innovation for replacing energy and materials based on the use of fossil fuels in various industrial processes. ${ }^{1}$ Taken together, they will have major repercussions on production systems, work organisation as well as job shift and transition. Climate transition is not only a grand challenge for Research \& Innovation (R\&l) and the European Innovation system. It also comprises the demand for new skills and educational investment on a scale far beyond present investment.

Today's skills will not match the jobs of tomorrow, and newly acquired skills may quickly become obsolete. The greening of our economies will create millions of jobs as we adopt sustainable practices and clean technologies, but other jobs will disappear, as countries scale back their carbon- and resource-intensive industries. ${ }^{2}$

\section{The erratic pandemic shocking working and living conditions in Europe}

On top of these twin challenges, the pandemic outbreak during 2020 has fundamentally changed the conditions of future work in many respects. The structural, economic, and social impact of Covid-19 on the labour market and working conditions has given the metaphor of The Black Swan a new, unexpected, and unhappy face. The first and second waves of the pandemic have in the short run significantly increased the levels of unemployment, and structural downsizing of specific sectors of the labour market, but also expanded in other sectors. Culture and entertainment and sports have more or less been locked down. Selfemployed persons, consultants and SMEs are facing increasingly tougher times with falling demand for services, not to mention people being caught in precarious work and uncertain and low paid working conditions. The transport sector, tourism and international travelling have also faced new restraints.

Hospitals, care for the elderly, and health promotion is an expanding sector carrying both risks and challenges. The industrial sector is facing a falling demand for their products and is also suffering from transport and national barriers and disruptive value and production chains. New forms of remote and collaborative work have created both opportunities and risks in the European workplace. The shift from offices to home-offices (hoffices) implies a new form of occupational time and place balance: and not all homes are always good

\footnotetext{
${ }^{1}$ https://www.klimatpolitiskaradet.se/en/rapport-2020/. Report from the Swedish Climate Policy Council.

2 Work for a brighter future. Global Commission on the future of work, ILO 2019
} 
workplaces. The pandemic has led to an open and uncontrolled experiment in new forms of work, and a fundamental change in what we define as a modern workplace, with far reaching impacts on work organisation, leadership, workers co-determination, health and safety and forms of workplace learning. The current development of workplace transformations due to Covid-19 has opened our eyes to look at the new home-based workplace, with respect to leadership, social interaction at work, tensions between work and life, as well as ergonomic angles.

As been pointed out by McKinsey recently, there is a large overlap between jobs at risk due to Covid-19 in the short term, and jobs displaced by automation in the longer term. ${ }^{3}$ The new panorama opens up dynamic transformations and learning processes of job destruction, job retention and job creation, as well as expansion of current jobs. And there is a growing risk that some groups, sectors, and regions might be lost in transition, which highlights the need for social protection in times of turbulent societal and industrial change.

\section{Are we, finally, approaching "the end of work"?}

Scenarios and projections of the future of work is a policy field in its "own. In 1995 the American futurist and policy thinker, Jeremy Rifkin presented his book The End of Work. The Decline of the Global Labor Force and the Dawn in the Post Market Area. Rifkin's ideas and contributions have been subject to criticism and discussion over the years. It also strengthens the scientific interest in the concepts of jobless growth and technological disruptions. Over the years, employment rates and number of full-time employees have shifted. Back in the mid-1990s there were deep concerns over growth and employment. In the public debate, there were two explanations for the weak performance of EU Member States: trade and technology.

Today, 25 years later, we know more about the interaction between tech-trade and employment. From 1995 to 2018, we have lived through a period of disruptive digital developments, a strong growth in global trade and investment, and a financial crisis. Despite this, there are 35 million more people employed in EU28 today compared to $1995^{4}$ - the highest employment rate ever in the EU (before the pandemic). This is the net result: it includes a loss of more than 5 million jobs during and after the financial and currency crises, from a peak in 2008 to a bottom in 2013, before the economic recovery. 15 million of these additional 35 million jobs have been created during 2013 to 2018.It is, however, difficult today to predict the job loss, employment slack and new jobs generated for the next years to come.

The same applies when we look at global development: according to the ILO, employment has increased by almost one billion jobs over 25 years, between 1991 and 2016, from 2,2 to 3,2 billion $^{5}$. In a short-term perspective, the impact of Covid-19 comprises not only job

\footnotetext{
${ }^{3}$ McKinsey (June 2020) The Future of Work in Europe. https://www.mckinsey.com/featured-insights/future-of-work

${ }^{4}$ http://appsso.eurostat.ec.europa.eu/nui/show.do?dataset=Ifsi emp a\&lang=en

${ }^{5}$ https://www.ilo.org/global/topics/future-of-work/publications/WCMS 591502/lang--en/index.htm
} 
destruction and job creation, but also jobs being reconstructed by functions and in time and place.

Whether we will see a continued employment growth, or not, is more a question of macroeconomic policies than digital technologies. The heavy employment losses between 2008 and 2013, 5 million jobs in EU28 can all be explained by mismanagement of the financial system, and of mistakes in macroeconomic policies, not by trade and technology. The good employment performance during 2014-2018 could be a seen as a learning experience for more growth-oriented policies: both monetary and fiscal policies, by the EU and the ECB and by Member States. The 2008 financial crisis was met by austerity and restrictions. The new double lockdown crises must be met by investments and fiscal policies to promote a healthy and productive recovery.

\section{The structural challenge: the two-speed-labour market}

The existing mismatch on the labour market can be illustrated by the metaphor of "the two speed labour market". It is a quite simple explanation of complex interactions between supply and demand. There are two sides of the labour market. On the one side there is the economy, businesses, big and small enterprises, public organisations, entrepreneurs: a mix of organisations, employing some 240 million people (before Covid-19). ${ }^{6}$

On the other side there is the labour force, 240 million employed: men and women, experienced workers and newcomers, skilled and unskilled, most of them in gainful employment, some of them entering the labour market, others in transition from one job to another. Then there are some 16 million unemployed, some of them, 6 million, long term unemployed. ${ }^{7}$

What do we know about the interaction between the economy and the labour force? We know that the pace of change in the economy is high. Some 10-20 per cent of new jobs are created in existing enterprises or in new ones, new jobs in the growing end of the economy, new jobs with new skills requirements. At the same time, existing jobs will be lost in the declining end of the economy. We also know that some of those losing their jobs will soon find a new job; however, many will not. Their skills from declining enterprises or positions, do not fit the new jobs. Redundancy, loss of jobs, will turn into unemployment. Too few are given a new start in the form of skills for the digital economy, existing skills do not match the changes in the economy, there will be bottlenecks in the growing end of the economy, and slower economic growth.

In the background document to the European Pillar of Social Rights, there are some striking facts from Member States on lack of action. As an average, only 10 per cent of those out of

\footnotetext{
${ }^{6}$ http://appsso.eurostat.ec.europa.eu/nui/show.do?dataset=Ifsi_emp_a\&lang=en

${ }^{7}$ http://appsso.eurostat.ec.europa.eu/nui/show.do?dataset=Ifsq_ugan\&lang=en
} 
work were offered a new start in the form of retraining or upskilling. Most of the jobseekers must find a new job in the digital economy, lacking skills for this new world of work. A report written by Michel Servoz, a former DG of DG Employment in the EU-Commission, confirms the two-speed labour market: on the one hand, 90 per cent of jobs now require IT-skills, on the other hand 61 million people in the EU have insufficient basic skills.

Thus, too few springboards inside enterprises, and too few bridges back to work, for those who have lost their jobs. Too much intervention comes too late, leading to long term unemployment. The message from the European employment strategies and the European Pillar of Social Rights is clear, much more must be done. Policies have, according to the OECD, a key role to play to promote an efficient and inclusive digital transformation, by ensuring that the necessary complementary factors are in place, including enhancing initial education and training systems' ability to provide the cognitive, technical and managerial skills that are crucial to striving in digital economies. ${ }^{8}$ Or, to quote the World Economic Forum: "We need a reskilling revolution"$"$.

To summarise: It is not only technology and globalisation that is the threat. It is the lack of supporting policies that is causing social and economic damage. This is a big European problem of the past, and it will be a bigger problem of tomorrow: unless there is fundamental change in Member States' political priorities.

\section{The skills gap is widening}

There are many ways to analyse and estimate the European Skill Gap. ${ }^{10}$ The Cedefop study (2018) describes various approaches to the problem. The challenge does not only comprise the digital divide and new digital skills. In a broader sense it is about the matching of skills and future jobs, bearing in mind the current discussion of how many jobs and skills that will become obsolete in the next two decades to come. The skills mismatch is not only, however, a question of underqualification, but also the problem of overqualification or overeducation. According to Eurostat (2020) there is no generally accepted method to estimate skill gaps in the labour market. ${ }^{11}$ One often used indicator is the recruitment gap, by enterprises reporting that they cannot find enough highly skilled and competent employees in their own field. Another approach is to ask employees about their need for skill upgrading, workplace learning and further education.

\footnotetext{
${ }^{8}$ http://www.oecd.org/eco/growth/digitalisation-productivity-and-inclusiveness/

${ }^{9}$ https://www.weforum.org/agenda/2019/04/skills-jobs-investing-in-people-inclusive-growth/

${ }^{10}$ https://www.cedefop.europa.eu/files/3075 en.pdf. Insights into skill shortages and skill mismatch. Learning from Cedefop's European skills and jobs survey. Cedefop 2018

${ }^{11}$ https://ec.europa.eu/eurostat/documents/7894008/9596077/Methodological note.pdf. Based on EU Labour Force Survey (EU-LFS) data, the agency proposes experimental indicators measuring the "vertical" and "horizontal" skills mismatch, i.e., discrepancies between educational attainment levels (ISCED 2011 1-digit) and occupations (ISCO 2008 1-digit). "Horizontal" measures focus on misalignments between the educational field of the highest level of education attained.
} 
A Cedefop estimate, based on European skills and jobs survey (ESJS, has shown that the existing skills of the EU's workforce fall about one fifth short of what is needed for workers to carry out their jobs at their highest productivity level. This calls for concerted action to stimulate further adult learning and training in Europe. This study also showed that $43 \%$ of EU employees experienced a recent change in the technologies they use at work. Digital technologies are used in many sectors of the labour market, and the demand for information and communications technology specialists is growing fast. In the future, 9 out of 10 jobs will require digital skills. At the same time, 169 million Europeans between 16 and 74 years: 44\%, do not have basic digital skills. ${ }^{12}$

A common method is to describe the education gap between generations, social group or men and women. According to Eurostat (2020) there are about 34\% of women in EU who have completed tertiary education, while $29 \%$ of men had reached this level. If we start, with the prediction that $50 \%$ of the workforce should have completed higher education level, we need a fundamental educational upgrading. Taking the alternative route and looking into vocational education and training, at least one in five employees need a longer skill upgrade for one year. Thirdly, the skill gaps can also be met by new combinations of workplace and job oriented short-cycle programmes.

\section{What is the EU response to the skills challenges?}

Recently, the Commission presented the European Skills Agenda for sustainable competitiveness, social fairness, and resilience. ${ }^{13}$ It underlines the need for upskilling of existing skills and reskilling for new tasks. It is a major challenge for Member States, companies, and social partners, that not only comprises formal education, but also nonformal and informal learning arenas in society and working life. To open a wider range of lifelong learning, the Commission suggests using "the EU budget as a catalyst to unlock public and private investment in people's skills".

The Skill Pact is a concerted action of various measures, from the promotion of Skills Intelligence and better matching between demand and supply on the labour market, national skill strategies, highlighting vocational education and training (VET) in a lifelong setting and reinforced by Centres of Vocational Excellence, higher education and up-skilling of scientists, promotion of STEM (Science, Technology, Engineering and Mathematics) skills, and investment in skills supporting the green deal and the digital revolution. Finally, the new skills pact stresses the fundamental role of transversal and generic skills. "Beyond technical skills, the labour market increasingly needs transversal skills like working together, critical thinking, and creative problem solving."

\footnotetext{
${ }^{12}$ https://ec.europa.eu/digital-single-market/en/news/digital-skills-gap-europe

${ }^{13}$ https://epale.ec.europa.eu/en/content/skills-agenda-sustainable-competitiveness-social-fairness-and-resilience
} 


\section{New springboards and new bridges to work}

In addition to reskilling and up-skilling, the combined impact of Covid-19, new green deal and digitalisation calls for new forms of career transition support. Helping employees' transition to new jobs and to re-orient themselves in the job market, are available to some extent in most countries. They are a means for attaining a fair labour market, as well as being a cog in social protection systems. These efforts come in many forms, and vary greatly between countries and over time.

Sweden has longstanding experience of Job Transition Funds, and the model bears resemblance to a collective insurance plan, which has proven quite successful. In Sweden: whenever restructuring involves reducing the size of the workforce, displaced persons have two main forms of support. In addition to the Swedish Public Employment Service (Arbetsförmedlingen), there are also several Job Transition Funds (or Job Security Councils) that provide support for new employment. The job security councils are independent of the state and are the result of collective bargaining agreements between social partners.

\section{The Social Partners' System for Transformation in Sweden}

The Swedish system, built on the social partners with job transitions funds/job security councils, results in comparatively short transition periods (between being laid off and finding a new job) and high success rates. About 90 per cent of people who receive help from job security councils are employed elsewhere within six to twelve months. It is important to note that this system is based on collective agreements, and therefore only covers people who are affected by such agreements. Trade union organisations and employer organisations work for their members. The idea is that those who are not covered by a collective agreement instead receive support from the public welfare system. These include for example newly arrived immigrants, recent graduates from school and higher education, and those who are self-employed. The goal is for displaced workers to find a new sustainable and lasting source of income.

The report "Back to Work: Sweden" from the OECD notes that 'Much of the Swedish success can be attributed to the role of social partners who have developed a solid infrastructure to anticipate economic changes on the one hand, and manage structural change via the socalled Job Security Councils on the other.'14 Although the Swedish system with job security councils is applied to uniquely Swedish experiences, and complements a labour model with a high level of representation of both workers and employers, aspects of the model can be translated and adapted to systems with a lower level of engagement. Essentially, the job security councils can most closely be compared to an insurance plan. The premium is paid

\footnotetext{
${ }^{14}$ OECD (2015), Back to Work: Sweden: Improving the Re-employment Prospects of Displaced Workers, Back to Work, OECD Publishing, Paris, https://doi.org/10.1787/9789264246812-en.
} 
monthly by employers as a portion of 0,3 to 0,6 percent of the salaries, and the insurance kicks in when restructuring is needed.

More generally, European welfare regimes have crucial and supporting functions for job transition and efficient labour market transformation. The levels of provision of good childcare and care for the elderly, are fundamental also for labour market participation, both for men and women. Social protection, equality of opportunities and the right to good working conditions are necessary preconditions for economic development and growth. It is also the core vision of the European Pillar of Social Rights and the important role of the social dialogue on the European labour market.

\section{What the EU and Member States must do}

For the EU to get out of the current crisis, it needs to generate recovery, build resilience, and guide economies along the path of just, green and digital transitions. The recovery will have to be inclusive and fair. The European Pillar of Social Rights provides a compass to tackle the social and economic challenges of our time. ${ }^{15}$

The intersection of SDG and European Pillar of Social Rights provides a joint arena for the Future of Work in Europe. The current development of "work without boundaries" has been articulated by new working patterns due to the pandemic. "Work-life balance" has taken a new shape in the context of remote work, hoffices, and distributed workplaces. The new uncertainty of future of work and instable employment conditions for groups at risk, highlights to crucial role of values and objectives in the European Pillar of Social Rights. In times of technological disruptions, increasing unemployment and close down of many businesses, it is important not only to secure social protection in general, but also to create targeted missions for groups at risks: e.g., workers with low education, individuals with disabilities, workers being discriminated at work in various contexts.

The New Skills Agenda for Europe is a good start to address the challenges of 2020+. However, the triple challenges: digitalisation, climate transition and the pandemic, requires new policies and new investment in skills and transition.

\section{A Mission}

We would suggest the inclusion in this Agenda of a Mission on" Skills for just transition and the digital transformation 2020-2030" like the ones introduced by Horizon Europe: for climate, health, food, and oceans.

This is a new form to drive innovation and investment through explicit missions and goals. Such a mission on skills should be supported by the whole financial value chain, all available

\footnotetext{
${ }^{15}$ https://ec.europa.eu/social/main.jsp?catld=1487\&langld=en
} 
financial resources at national and European levels, and all sectors of the economy. It should be a joint responsibility for the social partners to test new forms and to develop "best practice" in a co-creation process, supported by Horizon Europe and ESF+.

\section{New forms for transition mechanisms to be managed by the social partners}

In the context of fundamental labour market and social transformations, policies for decent and sustainable jobs must be integrated with decent, secure, and sustainable forms of job transitions. Institutions, models, and tools to facilitate job mobility should be core functions in the European social model, and, also supported at national level.

Models and experiments of European Job Security Councils, based on transition fund managed and controlled by the social partners in collaboration with national and local governments, could be a central measure in a European toolbox for job shift and transition.

\section{Just transition}

The new recovery fund Next Generation EU, and other policy measures and investments in the EU, must combine both shorter and longer perspectives. It cannot mainly function as a first aid kit of economic aid for the next months or years to come. Nor can it only highlight the long-term mission to support the green deal, profound measures to limit climate change. It is also crucial to achieve a balance between social rights and healthy living and working conditions for European citizens, and at the same time support a recovery and a restart of main economic sectors in society. ${ }^{16}$ The concept of "just transition" is crucial in an ecological sound transformation of industrial sectors, but it is highly important that it also considers the cost and benefits for the workers. ${ }^{17}$ Grand challenges for future Europe are to develop and integrated social model combining digitalisation, reducing CO2-emissions in industries, and through intensified electrification of the transport sector. In addition to abolition of fossildependent energy systems, it is necessary to combat increasing inequalities between and within countries.

\section{Workplace innovations}

The Green Deal calls for a new and fresh look at workplace innovations to respond to the needs of various sectors of working life, e.g., the energy sector, the industrial sector, public servicer as wells as the broader service sector. The greening of work does not only include "green jobs" in agriculture, forestry, and energy production, but also sustainable working condition and sustainable production systems and products. Flexible work organisations are often a missing link between labour market and employment policies on the one hand, and

\footnotetext{
${ }^{16}$ Another investment from the EU Commission to facilitate labour market related transitions is the temporary Support to mitigate Unemployment Risks in an Emergency (SURE), which aims at mobilising significant financial means to fight the negative economic and social consequences of the coronavirus outbreak in various countries.

17 https://www.etui.org/publications/socially-just-transition-through-european-green-deal
} 
policies for occupational safety and health, OSH, on the other. Modern and innovative work organisations are a set of keys to connect measures as the meso-level as labour market policies and labour laws with the micro level at firms, workplaces, or individual workers' situation. Al, algorithms, big data, and new technology will make many jobs obsolete, but also create new jobs as part of the gig-economy. The ongoing automation, $\mathrm{Al}$ and other technology-driven changes at the workplace will promote productive and growth, but can also support polarisation on the labour market and negative reactions for those left behind. It is a challenge for politicians and social partners to make soft transitions, so that people embrace rather than fear these developments.

The Green Deal must be implemented in a coalition between social partners, business, and governments with the aim of integrating the various dimensions of the SDG: i.e., ecological, economic, and social dimensions.

\section{New resources}

Even before the pandemic, there was a big and growing skills gap. With the pandemic the skills gap is widening further. It is not easy to predict the content, quality and volume of skill development needs caused by the triple challenge of climate change, digitalisation, and Covid-19. We suggest, however, that the EU Commission should develop a transition capacity indicator corresponding to at least one fifth of the labour force and to recommend new springboards and bridges to work for the next years to come.

We are convinced that this is the most productive and profitable investment Europe can make. That will include a doubling of the investment plans in the European Skills Agenda, and new priorities at the national level. New models of cost-sharing between individuals, corporations and public interests are needed to facilitate vocational training and up-grading of skills. Learning accounts, targeted models of social and economic support, leave of absence and open access are other investment fields. All these measures can be seen in the light of the European Pillar of Social Rights, here in combination with Learning Rights which are also being promoted by Agenda 2030 and the SDGs.

It will help enterprises to find workers with the right skills and workers to find the way back to gainful employment. It will reduce social cost. It will pay off both in the short and the long run.

\section{References}

https://ec.europa.eu/info/horizon-europe-next-research-and-innovation-framework-programme/mission-areaclimate-neutral-and-smart-cities en https://www.eurofound.europa.eu/publications/other/2020/priorities-for-a-new-europe https://ec.europa.eu/eurostat/web/european-pillar-of-social-rights https://ec.europa.eu/info/business-economy-euro/economic-and-fiscal-policy-coordination/financial-assistanceeu/funding-mechanisms-and-facilities/sure en 


\section{About the authors}

Allan Larsson is a former Swedish Social Democrat politician. From 1990 to 1991 he served as Minister for Finance. From 1995 to 2000, he served as Director for DG Employment, Social Affairs and Equal Opportunities in the European Commission. In January 2016, President of the European Commission Jean-Claude Juncker appointed Allan Larsson as a Special Adviser on the European Pillar of Social Rights. At present, Allan Larsson is member of the EU Mission Climate neutral and smart cities and the Swedish programme initiative of Viable Cities.

Kenneth Abrahamsson is a Swedish policy analyst and researcher in the field of work, education and learning. He is presently adjunct professor in human work science, Luleå university of technology and associate professor (docent), Department of Education, University of Stockholm. He has substantial experience as research administrator at various governmental agencies and research funders. He is now a senior consultant and is a member of the Swedish platform for sustainable work in Horizon 2020 and Horizon Europe. 